\title{
Ulcerative Colitis with Takayasu Disease
}

\author{
Yumi Asano Sachie Morita Kenta Iguchi Hiromi Kasugai Masahiko Inamori \\ Takashi Uchiyama Hiroshi lida Hiroki Endo Kunihiro Hosono Yasunari Sakamoto \\ Koji Fujita Masato Yoneda Hirokazu Takahashi Tomoko Koide Chikako Tokoro \\ Ayumu Goto Yasunobu Abe Noritoshi Kobayashi Kensuke Kubota Atsushi Nakajima
}

Gastroenterology Division, Yokohama City University Hospital, Yokohama, Japan

Dear Sir,

A 34-year-old Japanese woman with Takayasu disease was admitted to our hospital for bloody stool and anemia. A colonoscopy revealed redness and multiple small erosions along with a polypoid lesion in the ascending colon (fig. 1). The biopsy findings were compatible with the diagnosis of ulcerative colitis. Based on this diagnosis, the patient was started on prednisolone therapy (10 mg/day). Soon thereafter,

Fig. 1. A colonoscopy revealed redness and small erosions. the diarrhea, abdominal pain and bloody stool disappeared. Anemia also showed amelioration.

Takayasu disease is a rare vasculitis involving the aorta and its proximal branches. Both Takayasu disease and ulcerative colitis are chronic inflammatory diseases of unknown etiology, and neither is common in Japan; their coexistence, especially, is very rare $[1,2]$. It has been suggested that

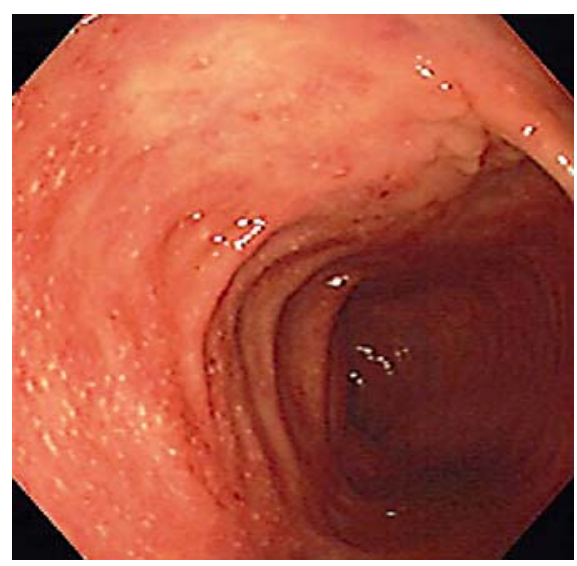

they could coexist because of cross-reactivity between autoantigens in the arterial wall and the colonic mucosa. Patients suffering from chronic inflammatory diseases, such as ulcerative colitis, must be investigated for other inflammatory diseases such as Takayasu disease. In conclusion, ulcerative colitis associated with Takayasu disease is rare, but is a significant problem in the clinical setting.

\section{References}

1 Ohta Y, Ohya Y, Fujii K, Tsuchihashi T, Sato $\mathrm{K}$, Abe I, Iida M: Inflammatory diseases associated with Takayasu's arteritis. Angiology 2003;54:339-344.

2 Sood A, Midha V, Sood N, Bansal M: Coexistence of Takayasu's arteritis with ulcerative colitis. J Assoc Physicians India 2006;54: 151-152.

\section{KARGER}

Fax +4161306 1234 E-Mail karger@karger.ch www.karger.com www.karger.com/dig
M. Inamori, $\mathrm{MD}, \mathrm{PhD}$

Gastroenterology Division, Yokohama City University Hospital

3-9 Fukuura, Kanazawa-ku, Yokohama, 236-0004 (Japan)

Tel. +81 45787 2640, Fax +81 457843546

E-Mail inamorim@med.yokohama-cu.ac.jp 